\title{
RESPON BEBERAPA GENOTIPE SORGUM (Sorgum bicolor [L.] Moench) TERHADAP SISTEM TUMPANGSARI DENGAN UBI KAYU (Manihot esculenta Crantz.)
}

\author{
Anggita Rahmawati, Muhammad Kamal \& Sunyoto \\ Jurusan Agroteknologi, Fakultas Pertanian Universitas Lampung \\ Jl. Prof. Soemantri Brodjonegoro, No. 1, Bandar Lampung 35145 \\ E-mail: anggita.rahmawati88@yahoo.co.id
}

\begin{abstract}
ABSTRAK
Sorgum (Sorghum bicolor [L]. Moench) adalah tanaman serealia yang mempunyai potensi besar untuk dikembangkan di Indonesia. Sistem tumpangsari sorgum dan ubi kayu merupakan cara untuk mengoptimalisasi penggunaan lahan. Penelitian ini bertujuan untuk mengetahui pertumbuhan dan produksi tanaman sorgum yang ditanam secara tumpangsari dan monokultur dengan ubi kayu dan mengetahui pengaruh genotipe pada pertumbuhan dan produksi tanaman sorgum yang ditumpangsarikan dengan ubi kayu. Penelitian dilaksanakan di Kebun Percobaan BPTP Lampung di Desa Negara Ratu, Kecamatan Natar, Kabupaten Lampung Selatan. Penelitian dilaksanakan pada November 2012 sampai April 2013. Dalam penelitian ini adalah lima genotipe sorgum yang digunakan yaitu Batan S3, Batan S12, Keller, Wray dan Numbu. Varietas ubi kayu yang digunakan adalah varietas Kasetsat. Perlakuan disusun secara faktorial dengan rancangan petak terbagi dalam rancangan kelompok teracak sempurna (RKTS) dengan tiga kali ulangan. Data dianalisis dengan sidik ragam dan perbedaan nilai tengah perlakuan dengan uji BNJ pada taraf 5\%. Petak utama adalah pola pertanaman sorgum dan anak petak adalah 5 genotipe sorgum. Dengan demikian jumlah petak dalam percobaan adalah 30 petak percobaan. Pertumbuhan dan hasil tanaman sorgum yang ditanam secara monokultur lebih baik dibandingkan dengan pertumbuhan dan hasil tanaman sorgum yang ditanama secara tumpangsari. Berdasarkan berat biji per malai perbedaan hasil tanaman sorgum pola tanam tumpangsari $(30,74 \mathrm{~g})$ dan monokultur $(37,26 \mathrm{~g})$ adalah $17,5 \%$. Berdasarkan rata-rata bobot biji per malai dan jumlah biji permalai hasil tanaman sorgum genotipe yang paling baik jika ditanam secara pola pertanaman tumpangsari dan monokultur secara berurutan, yaitu Numbu, Batan S3, Batan S12, Wray dan Keller dengan bobot biji per malai masing-masing genotipe yaitu 58,41 g, 36,04 g, 32,97 g, 21,04 g dan 21,53 g.
\end{abstract}

Kata kunci: Sorgum, tumpangsari, ubi kayu.

\section{PENDAHULUAN}

Peningkatan jumlah penduduk akan terus menuntut pemenuhan kebutuhan dasar terutama pangan dan energi dunia, termasuk Indonesia akan dihadapkan pada krisis untuk memenuhi kedua kebutuhan dasar tersebut akibat semakin terbatasnya sumber daya (Suwarto, 2012).

Sorgum (Sorghum bicolor [L]. Moench) adalah tanaman serealia yang mempunyai potensi besar untuk dikembangkan di Indonesia karena mempunyai daerah adaptasi yang luas (Sucipto, 2010).

Optimalisasi produktifitas lahan menjadi prioritas dalam pengembangan budidaya pertanian. Salah satu bentuknya adalah dengan pola tumpang sari (Prasetyo et al. 2009). Tumpangsari merupakan suatu usaha menanam beberapa jenis tanaman pada lahan dan waktu yang sama. Penanaman dengan cara ini bisa dilakukan pada dua atau lebih jenis tanaman yang relatif seumur, misalnya jagung dan kacang tanah atau bisa juga pada beberapa jenis tanaman yang umurnya berbeda-beda.
Kesalahan dalam menentukan jenis tanaman yang akan ditumpangsarikan dapat membuat yang sebenarnya menjadi kelebihan pola tanam tumpangsari menjadi kelemahan tumpang sari (Master, 2013). Ubi kayu di Indonesia merupakan makanan pokok ke tiga setelah padi-padian dan jagung (Dirjen Perkebunan, 2012).

Menurut Herawati et al. (2012) dan Kamal (2011), salah satu keunggulan sistem tumpangsari sorgum dan ubi kayu adalah produktifitas lahan per satuan lahan akan meningkat karena produksi tanaman pokok ubi kayu tetap dan mendapat tambahan produksi sorgum. Dengan demikian sistem pola pertanaman tumpangsari ubi kayu dan sorgum merupakan alternatif pengembangan sorgum pada wilayah yang di dominasi pertanaman ubi kayu, khususnya daerah Lampung.

Penelitian ini bertujuan untuk mengetahui pertumbuhan dan produksi tanaman sorgum yang ditanam secara tumpangsari dan monokultur dengan ubi kayu, selain itu untuk mengetahui pengaruh genotipe pada pertumbuhan dan produksi tanaman sorgum yang ditumpangsarikan dengan ubi kayu. 


\section{BAHAN DAN METODE}

Penelitian dilaksanakan di Kebun Percobaan Badan Pengkajian Teknologi Pertanian (BPTP) Lampung di Desa Negara Ratu, Kecamatan Natar, Kabupaten Lampung Selatan. Penelitian dilaksanakan pada November 2012 sampai April 2013. Perlakuan disusun secara faktorial dengan rancangan petak terbagi dalam rancangan kelompok teracak sempurna (RKTS) dengan tiga kali ulangan. Petak utama adalah pola pertanaman sorgum yang terdiri atas pola tanam sistem tumpang sari dan sistem monokultur. Anak petak adalah 5 genotipe sorgum yang terdiri dari Batan S3, Batan S12, Keller, Wray dan Numbu. Dengan demikian jumlah petak pecobaan adalah 30 petak percobaan dengan ukuran 3,2 m x $4 \mathrm{~m}$.

Varietas ubi kayu yang digunakan adalah Kasersart dan jarak tanaman yang digunakan adalah $20 \mathrm{~cm} \times 80 \mathrm{~cm}$ untuk tanaman sorgum dan jarak tanam ubi kayu $60 \mathrm{~cm}$ x $80 \mathrm{~cm}$. Komponen pertumbuhan tanaman sorgum meliputi tinggi tanaman $(\mathrm{cm})$, jumlah daun (helai), diameter batang (cm), umur berbunga (hst), tingkat kehijauan daun dan komponen hasil meliput panjang malai $(\mathrm{cm})$, bobot kering malai $(\mathrm{g})$, jumlah biji per malai (butir), bobot biji per malai (g) dan bobot 100 butir biji (g).

\section{HASIL DAN PEMBAHASAN}

Pola pertanaman berpengaruh nyata terhadap jumlah daun pada umur 2 mst, tingkat kehijauan daun pada umur 4, 6, 8, dan $10 \mathrm{mst}$, panjang malai, bobot biji permalai dan bobot 100 butir biji (Tabel 2, 4 dan 5). Genotipe tanaman sorgum berpengaruh terhadap tinggi tanaman umur 8 dan $10 \mathrm{mst}$, diameter batang pada umur 4 dan 6 mst, panjang malai, bobott kering malai, bobot biji per malai, bobot 100 butir biji, dan jumlah biji per malai (Tabel 1, 3, dan 5).

Hasil penelitian respon beberapa genotipe sorgum (Sorgum bicolor [L.]Moench) terhadap sistem tumpangsari dengan ubi kayu (Manihot esculenta Crantz) menunjukan bahwa pertumbuhan dan hasil tanaman sorgum yang ditanam secara monokultur cenderung lebih baik dibandingkan dengan pertumbuhan dan hasil tanaman sorgum yang ditanama secara tumpangsari. Hal ini karena kompetisi cahaya dan unsur hara pada pola pertanaman monokultur lebih kecil dibandingkan dengan pola pertanaman tumpangsari, sehingga tanaman dapat tumbuh dan berkembang lebih baik (Tabel 1, 2, 3, 4 dan 5). Pada sistem tumpangsari tajuk ubi kayu menaungi tanaman sorgum sehingga penyerapan cahaya menjadi kurang optimal, sedangkan untuk menghasilkan produksi yang baik tanaman sorgum membutuhkan energi cahaya yang tinggi. Hamim et al (2012) menyatakan tajuk ubi kayu tumbuh lebih dominan akan menaungi tanaman sorgum, sehingga sorgum mengalami defisit cahaya.

Umumnya tanaman yang memiliki pertumbuhan tanaman lebih tinggi akan diikuti dengan jumlah daun yang lebih banyak dan diameter batang yang lebih besar serta tingkat kehijauan daun yang tinggi karena penyerapan energi cahaya untuk berlangsungnya metabolisme dalam organ tumbuhan lebih baik dan dapat terpenuhi, sehingga berpengaruh terhadap hasil tanaman

Tabel 1. Pengaruh pola pertanaman dan genotipe sorgum terhadap tinggi tanaman sorgum pada umur 2, 4, 6, 8 dan 10 mst.

\begin{tabular}{|c|c|c|c|c|c|}
\hline \multirow{2}{*}{ Perlakuan } & \multicolumn{5}{|c|}{ Umur Tanaman (mst) } \\
\hline & 2 & 4 & 6 & 8 & 10 \\
\hline \multicolumn{6}{|l|}{ Pola Pertanaman } \\
\hline Monokultur & $19,28 \mathrm{a}$ & $46,45 \mathrm{a}$ & $92,68 \mathrm{a}$ & $149,53 \mathrm{a}$ & $219,50 \mathrm{a}$ \\
\hline Tumpang sari & 19,49 a & $51,77 \mathrm{a}$ & $100,52 \mathrm{a}$ & $184,06 \mathrm{a}$ & $217,25 \mathrm{a}$ \\
\hline \multicolumn{6}{|l|}{ Genotipe } \\
\hline Batan S3 & 16,76 a & $41,70 \mathrm{a}$ & 82,76 a & $119,20 \mathrm{~b}$ & $145,13 \mathrm{c}$ \\
\hline Batan S12 & 20,06 a & $51,00 \mathrm{a}$ & $94,70 \quad \mathrm{a}$ & $129,93 \mathrm{ab}$ & $168,10 \mathrm{~b}$ \\
\hline Keller & 16,63 a & 43,90 a & $92,20 \quad a$ & $160,30 \mathrm{ab}$ & $269,10 \mathrm{ab}$ \\
\hline Wray & 20,06 a & $47,86 \mathrm{a}$ & 89,63 a & $151,73 \mathrm{ab}$ & $231,16 \mathrm{ab}$ \\
\hline Numbu & $23,40 \mathrm{a}$ & $61,10 \mathrm{a}$ & $123,70 \mathrm{a}$ & 189,86 a & $278,40 \mathrm{a}$ \\
\hline
\end{tabular}

Keterangan: Angka-angka yang diikuti huruf yang sama pada kolom dan perlakuan yang sama tidak berbeda nyata menurut uji BNJ pada $\alpha_{0,05}$. 
Tabel 2. Pengaruh pola pertanaman dan genotipe sorgum terhadap jumlah daun tanaman sorgum pada umur 2, 4, 6,8 dan 10 mst.

\begin{tabular}{|c|c|c|c|c|c|}
\hline \multirow{2}{*}{ Perlakuan } & \multicolumn{5}{|c|}{ Umur Tanaman (mst) } \\
\hline & 2 & 4 & 6 & 8 & 10 \\
\hline Pola Pertanaman & \multicolumn{5}{|c|}{.. helai } \\
\hline Monokultur & $4,17 \mathrm{a}$ & $5,85 \mathrm{a}$ & $7,02 \mathrm{a}$ & $8,26 \mathrm{a}$ & $8,61 \mathrm{a}$ \\
\hline Tumpangsari & $3,65 \mathrm{~b}$ & $5,56 \mathrm{a}$ & $6,82 \mathrm{a}$ & $8,25 \mathrm{a}$ & $9,10 \mathrm{a}$ \\
\hline \multicolumn{6}{|l|}{ Genotipe } \\
\hline Batan S3 & $3,90 \mathrm{a}$ & $5,43 \mathrm{a}$ & $6,76 \mathrm{a}$ & $8,03 \mathrm{a}$ & $7,93 \mathrm{a}$ \\
\hline Batan S12 & $3,93 \mathrm{a}$ & $5,76 \mathrm{a}$ & $6,76 \mathrm{a}$ & $7,60 \mathrm{a}$ & $8,20 \mathrm{a}$ \\
\hline Keller & $3,56 \mathrm{a}$ & $5,43 \mathrm{a}$ & $6,73 \mathrm{a}$ & $8,36 \mathrm{a}$ & $9,13 \mathrm{a}$ \\
\hline Wray & $4,30 \mathrm{a}$ & $5,93 \mathrm{a}$ & $6,90 \mathrm{a}$ & $8,73 \mathrm{a}$ & 9,46 a \\
\hline Numbu & $3,86 \mathrm{a}$ & $5,96 \mathrm{a}$ & $7,46 \mathrm{a}$ & $8,56 \mathrm{a}$ & $9,56 \mathrm{a}$ \\
\hline
\end{tabular}

Keterangan: Angka-angka yang diikuti huruf yang sama pada kolom dan perlakuan yang sama tidak berbeda nyata menurut uji BNJ pada $\alpha_{0,05}$.

Tabel 3. Pengaruh pola pertanaman dan genotipe sorgum terhadap diameter batang tanaman sorgum pada umur 4, 6,8 dan 10 mst.

\begin{tabular}{|c|c|c|c|c|}
\hline \multirow{2}{*}{ Perlakuan } & \multicolumn{4}{|c|}{ Umur Tanaman (mst) } \\
\hline & 4 & 6 & 8 & 10 \\
\hline Pola Pertanaman & \multicolumn{4}{|c|}{ 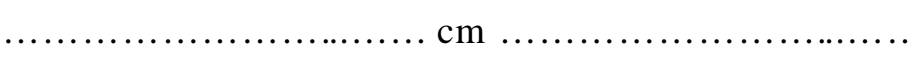 } \\
\hline Monokultur & $0,85 \mathrm{a}$ & $1,01 \mathrm{a}$ & $1,57 \mathrm{a}$ & $1,89 \mathrm{a}$ \\
\hline Tumpang sari & $0,82 \mathrm{a}$ & $0,97 \mathrm{a}$ & $1,48 \mathrm{a}$ & $1,81 \mathrm{a}$ \\
\hline \multicolumn{5}{|l|}{ Genotipe } \\
\hline Batan S3 & $0,85 \mathrm{ab}$ & $1,03 \mathrm{ab}$ & $1,55 \mathrm{a}$ & $1,89 \mathrm{a}$ \\
\hline Batan S12 & $0,84 \mathrm{ab}$ & $1,00 \mathrm{abc}$ & $1,62 \mathrm{a}$ & $1,89 \mathrm{a}$ \\
\hline Keller & $0,76 \mathrm{~b}$ & $0,91 \mathrm{c}$ & $1,44 \mathrm{a}$ & $1,77 \mathrm{a}$ \\
\hline Wray & $0,81 \mathrm{ab}$ & $0,94 \mathrm{bc}$ & $1,44 \mathrm{a}$ & $1,73 \mathrm{a}$ \\
\hline Numbu & $0,91 \mathrm{a}$ & 1,08 aа & $1,59 \mathrm{a}$ & $1,97 \mathrm{a}$ \\
\hline
\end{tabular}

Keterangan: Angka-angka yang diikuti huruf yang sama pada kolom dan perlakuan yang sama tidak berbeda nyata menurut uji BNJ pada $\alpha_{0,05}$.

tersebut. Akan tetapi, dalam penelitian ini tinggi tanaman sorgum tidak diikuti oleh penambahan jumlah daun, diameter batang dan tingkat kehijauan daun tanaman sorgum pada setiap genotipe yang diuji, dapat dilihat pada (Tabel 1, 2, 3, dan 4), sehingga mempengaruhi produksi tanaman sorgum. Pertumbuhan tanaman yang berbeda menghasilkan produksi yang berbeda pula pada setiap genotipenya (Tabel 5).

Hal ini dapat terjadi pada penelitian ini karena pertumbuhan dan hasil tanaman sorgum dipengaruhi oleh faktor genetik dan lingkungan. Seperti yang dinyatakan oleh Budiman (2005) yaitu faktor gen merupakan faktor penurunan sifat pada keturunan yang terkandung didalam genotipe. Informasi genetik pada gen mengendalikan terbentuknya penampakan sifat secara fisik melalui interaksinya dengan faktor lingkungan. Genetik sorgum dalam penelitian ini memiliki sifat pertumbuhan dan hasil sorgum yang berbeda-beda pada setiap genotipe yang diuji.

Selain itu faktor lingkungan juga berpengaruh terhadap pertumbuhan dan hasil tanaman sorgum. Kamal (2011) mengungkapkan bahwa perubahan iklim bisa berdampak pada perubahan distribusi radiasi surya. Pada bulan-bulan yang didominasi oleh hari-hari hujan akan menyebabkan intensitas radiasi rendah. Penurunan intensitas radiasi dapat menekan pertumbuhan tanaman yang pada akhirnya dapat menurunkan produksi tanaman pangan. Perubahan perilaku radiasi juga dapat 
Tabel 4. Pengaruh pola pertanaman dan genotipe sorgum terhadap tingkat kehijauan daun tanaman sorgumpada umur 4, 6, 8 dan 10 mst.

\begin{tabular}{lcccc}
\hline Perlakuan & \multicolumn{5}{c}{ Umur Tanaman (mst) } \\
\cline { 2 - 5 } & 4 & 6 & 8 & 10 \\
\hline Pola Pertanaman & & & \\
Monokultur & $35,52 \mathrm{a}$ & $39,95 \mathrm{a}$ & $43,82 \mathrm{a}$ & $47,12 \mathrm{a}$ \\
Tumpangsari & $32,83 \mathrm{~b}$ & $35,86 \mathrm{~b}$ & $39,38 \mathrm{~b}$ & $44,03 \mathrm{~b}$ \\
Genotipe & & & & \\
Batan S3 & $35,12 \mathrm{a}$ & $39,81 \mathrm{a}$ & $43,22 \mathrm{a}$ & $47,75 \mathrm{a}$ \\
Batan S12 & $35,96 \mathrm{a}$ & $37,60 \mathrm{a}$ & $42,60 \mathrm{a}$ & $45,69 \mathrm{a}$ \\
Keller & $33,35 \mathrm{a}$ & $37,93 \mathrm{a}$ & $40,24 \mathrm{a}$ & $43,61 \mathrm{a}$ \\
Wray & $32,62 \mathrm{a}$ & $35,25 \mathrm{a}$ & $38,73 \mathrm{a}$ & $43,70 \mathrm{a}$ \\
Numbu & $33,82 \mathrm{a}$ & $38,95 \mathrm{a}$ & $43,20 \mathrm{a}$ & $47,13 \mathrm{a}$ \\
\hline
\end{tabular}

Keterangan: Angka-angka yang diikuti huruf yang sama pada kolom dan perlakuan yang sama tidak berbeda nyata menurut uji BNJ pada $\alpha_{0,05}$.

Tabel 5. Pengaruh pola pertanaman dan genotipe sorgum terhadap waktu berbunga, panjang malai, bobotkering malai, bobot biji per malai, bobot 100 butir biji, dan jumlah biji per malai.

\begin{tabular}{lcccccc}
\hline \multicolumn{1}{c}{ Perlakuan } & WB $(\mathrm{hst})$ & PM $(\mathrm{cm})$ & BKM $(\mathrm{g})$ & BBM $(\mathrm{g})$ & B100 (g) & JBM (butir) \\
\hline Pola Pertanaman & & & & & & \\
Monokultur & $73,33 \mathrm{a}$ & $28,28 \mathrm{a}$ & $5,99 \mathrm{a}$ & $37,26 \mathrm{a}$ & $2,35 \mathrm{a}$ & $1463,83 \mathrm{a}$ \\
Tumpangsari & $72,33 \mathrm{a}$ & $25,59 \mathrm{~b}$ & $5,09 \mathrm{a}$ & $30,74 \mathrm{a}$ & $2,05 \mathrm{~b}$ & $1177,87 \mathrm{~b}$ \\
Genotipe & & & & & & \\
Batan S3 & $71,33 \mathrm{a}$ & $33,55 \mathrm{a}$ & $4,59 \mathrm{~b}$ & $36,04 \mathrm{~b}$ & $1,87 \mathrm{~b}$ & $1257,43 \mathrm{~b}$ \\
Batan S12 & $71,00 \mathrm{a}$ & $30,35 \mathrm{ab}$ & $5,66 \mathrm{~b}$ & $32,97 \mathrm{~b}$ & $1,82 \mathrm{~b}$ & $1405,03 \mathrm{~b}$ \\
Keller & $72,66 \mathrm{a}$ & $26,63 \mathrm{bc}$ & $4,73 \mathrm{~b}$ & $21,53 \mathrm{~b}$ & $1,81 \mathrm{~b}$ & $927,33 \mathrm{~b}$ \\
Wray & $73,83 \mathrm{a}$ & $22,96 \mathrm{~cd}$ & $3,98 \mathrm{~b}$ & $21,04 \mathrm{~b}$ & $1,86 \mathrm{~b}$ & $1008,33 \mathrm{~b}$ \\
Numbu & $75,33 \mathrm{a}$ & $21,18 \mathrm{~d}$ & $8,74 \mathrm{a}$ & $58,41 \mathrm{a}$ & $3,62 \mathrm{a}$ & $2006,10 \mathrm{a}$ \\
\hline
\end{tabular}

Keterangan: Angka-angka yang diikuti huruf yang sama pada kolom dan perlakuan yang sama tidak berbeda nyata menurut uji BNJ pada $\alpha_{0.05}$. WB = waktu berbunga, $\mathrm{PM}=$ panjang malai, $\mathrm{BKM}=$ bobot kering malai, BBM = bobot biji per malai, B100 = bobot 100 butir biji, dan JBM = jumlah biji per malai.

berpengaruh pada sirkulasi udara dan kelembaban udara.

Penelitian ini ditunjang oleh penelitian yang dilakukan oleh Rosnawati (2011) tentang pengaruh intensitas cahaya matahari terhadap pertumbuhan kedelai yang ditumpangsarikan dengan jagung menunjukan bahwa tinggi tanaman dan jumlah daun berbeda secara signifikan. Tanaman yang ditanam secara monokultur lebih baik dibandingkan yang ditanam secara tumpangsari. Hal ini berarti pola pertanaman tumpangsari berpengaruh terhadap tinggi dan jumlah daun tanaman kedelai. Perbedaan antara pertumbuhan tinggi tanaman dan jumlah daun antara kedelai yang ditumpangsari dan monokultur adalah $30,25 \%$.
Dari hasil analisis data yang dilakukan menunjukan bahwa pertumbuhan dan hasil tanaman sorgum yang ditanam secara monokultur lebih baik dibandingkan dengan pertumbuhan dan hasil tanaman sorgum yang ditanama secara tumpangsari. Berdasarkan berat biji per malai perbedaan hasil tanaman sorgum pola tanam tumpangsari $(30,74 \mathrm{~g})$ dan monokultur $(37,26 \mathrm{~g})$ adalah $17,5 \%$. Berdasarkan rata-rata bobot biji per malai dan jumlah biji permalai hasil tanaman sorgum genotipe yang paling baik jika ditanam secara pola pertanaman tumpangsari dan monokultur secara berurutan, yaitu Numbu, Batan S3, Batan S12, Wray dan Keller dengan bobot biji per malai masing-masing genotipe yaitu 58,41 g, 36,04 g, 32,97 g, 21,04 g dan 21,53 g. 


\section{KESIMPULAN}

Kesimpulan dari penelitian ini adalah pertumbuhan dan hasil tanaman sorgum yang ditanam secara monokultur lebih baik dibandingkan dengan pertumbuhan dan hasil tanaman sorgum yang ditanam secara tumpangsari dan genotipe berpengaruh terhadap hasil tanaman sorgum. Genotipe yang menunjukan hasil tertinggi pada sistem tumpangsari dengan ubi kayu dan sistem monokultur berdasarkan bobot biji per tanaman secara berurutan adalah Numbu, Batan S3, Batan S12, Wray dan Keller.

\section{SANWACANA}

Penulis mengucapkan terimakasih kepada Dr. Ir. Agus Karyanto, M.Sc. atas bimbingan dan kerjasamanya selama penelitian.

\section{DAFTAR PUSTAKA}

Budiman. 2005. http://budiman.www.id/faktor-yangmempengaruhi pertumbuhan-dan prkembangan-pada-pertumbuhan.html. Diakses pada tanggal 8 Juli 2013.

Direktorat Jendral Perkebunan. 2012. Sorgum manis komoditi harapan di propinsi kawasan timur Indonesia. Risalah Prospek Tanaman Sorgum untuk Pengembangan Agroindustri. Maret 2011. Edisi Khusus Balai Penelitian Tanaman Kacang-Kacangan dan Umbi-Umbian. No.42012: hal 7-15.

Hamim, H., R. Larasati dan M. Kamal. 2012. Analisis komponen hasil sorgum yang ditanam tumpangsari dengan ubi kayu dan waktu tanam berbeda. Prosiding Simposium dan Seminar Bersama PERA GI - PERHORT I - P ER I PI - H IG I Mendukung Kedaulatan Pangan dan Energi yang Berkelanjutan. Bogor, 1-2 Mei 2012. Hlm 91-94.
Kamal, M. 2011. Kajian Sinergi Pemanfaatan Cahaya dan Nitrogen Dalam Produksi Tanaman Pangan. Pidato ilmiah dalam rangka pengukuhan guru besar dalam bidang ilmu tanaman Fakultas Pertanian Universitas Lampung di Bandar Lampung tanggal 23 Februari 2011. Penerbit Universitas Lampung, Bandar Lampung. $68 \mathrm{hlm}$.

Master. 2013. Pola Tanam Tumpangsari. www.anakagronomy.com $/ 2013 / 03 /$ polatanam-tumpangsari.htm. Diakses pada tanggal 7 Juni 2013.

Prasetyo, E.I. Sukardjo dan H. Pujiwati. 2009. Produktivitas lahan dan NKL pada tumpang sari jarak pagar dengan tanaman pangan. Jurnal Akta Agrosia. Vol.12 No.1 : hal 51-55.

Rosnawati, N. 2011. Pengaruh intensitas cahaya matahari terhadap pertumbuhan tanaman kedelai yang ditumpangsarikan dengan tanaman jagung. Skripsi. Fakultas Pertanian. Universitas Andalas. Padang. Hlm 49.

Sucipto. 2010. Efektifitas cara pemupukan terhadap pertumbuhan dan hasil beberapa varietas sorghum manis. Jurnal Embryo. Vol.7 No.2. Hlm 6-7.

Suwarto. 2012. Menjadikan ubi kayu sebagai sumber ketahanan pangan dan energi di Indonesia. Prosiding Simposium dan Seminar Bersama PERA GI-PERHORT I - P ER I PI - H I G I Mendukung Kedaulatan Pangan dan Energi yang Berkelanjutan. Bogor 1-2 Mei 2012. Hlm 91-94. 